J. Lake Sci. (湖泊科学), $2007, \mathbf{1 9 ( 6 ) : 7 1 8 - 7 2 6 ~}$

http://www. jlakes.org. E-mail:jlakes@ niglas. ac.cn

(c) 2007 by Journal of Lake Sciences

\title{
抚仙湖集水域地表径流入湖水量模拟”
}

\author{
徐金涛 $^{1,2}$, 张 奇 $^{1 * *}$, 徐力刚 ${ }^{1}$
}

( $1:$ 中国科学院南京地理与湖泊研究所,南京 210008)

(2: 中国科学院研究生院, 北京 100049)

摘 要: 采用适用于无资料流域、参数较少的 SCS 模型计算抚仙湖集水域地表径流量. 模型考虑了集水域下垫面条件的 空间差异,利用 MapInfo/Arc view 软件按照土地利用方式与土壤类型的不同, 把集水域划分为若干个水文响应单元, 分别 计算产流量,较准确地模拟了人湖径流量. 通过对梁王河流域和大鲫鱼沟流域实测降雨径流资料的分析与反演, 提出了 适合该区域的产流计算 $\mathrm{CN}$ 值. 在对 $\mathrm{CN}$ 值作坡度修正后再应用到其它无观测数据区域. 通过模型计算得到的抚仙湖集 水域 2005 年 3 月 1 日 - 2006 年 2 月 28 日地表径流量为 $1.74 \times 10^{8} \mathrm{~m}^{3}$, 陆面径流系数为 0.395 . 模型为指导抚仙湖集水域 径流观测及人湖污染物负荷的计算提供依据.

关键词: SCS 模型; 地表径流; 抗仙湖集水域; CN 值

\section{Surface runoff modeling of Lake Fuxian catchment}

\section{XU Jintao ${ }^{1,2}$,ZHANG Qi ${ }^{1} \&$ XU Ligang ${ }^{1}$}

(1:Nanjing Institute of Geography and Limnology, Chinese Academy of Sciences, Nanjing 210008, P. R. China) (2:Graduate School, Chinese Academy of Sciences, Beijing 100049, P. R. China)

\begin{abstract}
SCS model is adopted in this paper to simulate surface runoff for Lake Fuxian catchment. The model considers the spatial diversities of the land surface via dividing the catchment into a number of hydrological response units (HRU) based on different landuses and soil types. The surface runoff for each HRU is calculated and the total surface runoff into the lake is modeled. CN values of the SCS model are calibrated by matching the modeled results with the observed ones for the gauged river catchments of Liangwanghe and Dajiyugou. The model is then applied to other ungauged areas of Lake Fuxian catchment after making slope corrections of the CN values. The model indicates that the total surface runoff is 174 million $\mathrm{m}^{3}$ for a one-year period of March 2005 to February 2006, with an average runoff coefficient of 0.395 . The model is believed to be helpful in guiding further field observations. The modeled results are also useful in constructing more detailed hydrological models as the next step, and in calculating mass of pollutants loaded to the lake.
\end{abstract}

Keywords: SCS model; surface runoff; Lake Fuxian catchment; CN value

湖泊的污染主要来自流域人类活动产生的含氮、磷等的污染物, 它们在降雨和径流等载体的作用下进 人湖中. 污染物进入湖泊的路径及负荷量的计算非常复杂,但河道径流、坡面散流和浅层地下水流等径流 携带污染物最多, 因此径流入湖水量的模拟也极为关键. 美国、欧洲、澳大利亚等国家和地区, 已经开发了 针对不同类型流域、不同研究目的各种模型, 实际应用中取得了令人满意的成果 ${ }^{[1-4]}$.

位于云南省境内的抚仙湖,近年来已出现了富营养化趋势, 因为其生态系统非常脆弱,应引起足够的重 视. 在污染物的输移中地表径流是最主要的载体, 其人湖水量的模拟也是抚仙湖研究中最关心的问题之

* 国家自然科学基金 (40471018)、中国科学院“百人计划”、南京地理与湖泊研究所所长基金( CXNIGLAS - 2004 - 1, CXNIGLAS - 2005-20) 和教育部留学回国人员科研启动基金联合资助. 2006-10-20 收稿;2006-12-30 收修改 稿. 徐金涛,男,1982 年生, 硕士研究生;E-mail:jtxu@ niglas. ac. cn.

** 通讯作者;E-mail:qzhang@ niglas. ac. cn. 
一. 抚仙湖陆地集水域坡度大、汇流功能弱的特点导致集水域存在上百条短浅的河流以及若干河流之间的 散流区. 以往对抚仙湖地表径流人湖水量的计算大多采用经验径流系数法 ${ }^{[5]}$, 结果较为粗粘, 而且整个集 水域都用同一个径流系数不能体现出由于下垫面不同而造成的产流空间差异以及人类活动对径流的影响. 但研究区域资料缺乏的限制又使得需要大量数据的分布式模型暂且难以应用. 本文采用结构简单、可应用 于无资料地区的 SCS 模型计算抚仙湖集水域地表径流人湖水量, 以期对研究区径流年内分布和人湖总量有 初步的认识, 为更详细的研究作准备,也为人湖污染负荷的计算提供径流数据.

\section{1 抚仙湖集水域概况}

\section{1 研究区域概述}

抚仙湖位于云南省中部玉溪市, 湖南北向长 $31.5 \mathrm{~km}$, 东西向平均宽度 $6.7 \mathrm{~km}$, 水面面积为 $212.0 \mathrm{~km}^{2}$, 最大水深为 $157.3 \mathrm{~m}$, 平均容水量 $189.3 \times 10^{8} \mathrm{~m}^{3}$ (图 1). 抚仙湖属珠江流域南盘江水系, 湖东岸海口河为唯 一的出水口, 属半封闭高原湖泊. 临湖东西两侧山坡陡峭, 全湖河道大多短小, 坡降较大, 产流条件较好 ${ }^{[5]}$. 湖水主要补给除雨季湖四周河流沟溪汇水汇集外,少部分由地下水补充.

抚仙湖处于亚热带常绿阔叶林 - 红壤地带, 雨量充沛. 沿岸土地利用类型主要为牧草地、水田,另有部 分灌木林、疏林、密林、旱地和难于利用的石山、荒山坡地, 沿湖有许多居住用地、旅游设施和基础设施用地. 由于成土母质的不同,抚仙湖沿岸除北岸的龙街、右所及南岸的张营一带为水稻土外,大多为石灰岩红壤、 玄武岩红壤, 次之为酸性紫色土 ${ }^{[6]}$. 据统计, 在各种土地利用类型中, 牧草地占集水域面积的 $54.6 \%$; 水田 占 $15.8 \%$; 林地占 $19.2 \%$; 旱地占 $5.3 \%$, 其它类型面积占 $5.1 \%$. 在各种土壤类型中,红壤占 $66.9 \%$; 水稻 土占 $12.2 \%$; 紫色土占 $13.9 \%$, 其它类型占 $7.0 \%$.

抚仙湖具有饮用水源、渔业、工农业用水、旅游等功能,是当地经济发 展的重要基础. 近几年, 受流域内人类活动的影响, 湖泊的污染逐渐加 重, 部分河道水土流失严重, 水质呈逐年下降趋势. 目前, 已在湖滨带建 设了若干人工湿地,有效地拦截了来自农田径流区的污染物 ${ }^{[7]}$. 为了进 一步弄清污染物产出的空间分布和强度, 更有针对性地拦截污染物的输 移, 目前正在集水域开展较为系统的径流过程和污染物迁移的现场观测, 安装了多台降雨、径流观测仪器, 并采用数学模型进行径流模拟, 以定量 揭示集水域的径流产出及其携带的污染物产出量.

\section{2 现场观测及模拟}

抚仙湖集水域陆地面积约为 $460 \mathrm{~km}^{2}$, 域内地形高程起伏大 (地面高 程从 $1500-2780 \mathrm{~m}$ 左右, 高程差在 $1300 \mathrm{~m}$ 左右)、河床坡降大 (东、西两 岸河床的平均坡降达 $11.2 \%-10.3 \%$, 北岸平坦区为 $4.8 \%$ )、河流集水 面积小 (除少数河流 $50 \mathrm{~km}^{2}$ 以上外, 其余多在 $30 \mathrm{~km}^{2}$ 以下). 由于河道短 浅,河道间部分地表径流无法汇人河道,而以坡面散流形式人湖. 这部分 径流占全部地面径流较大的比重, 但很难通过现场观测获得, 只有依靠模 型作计算分析. 在湖滨带, 往往有相当一部分地面径流不汇人河流, 而是 以散流形式直接入湖,这是湖泊集水域的特点之一.

通过野外实地调查, 抚仙湖集水域共有大小入湖河流 100 多条(含季 节河、农灌沟). 在人口相对集中的流域北部和南部地区, 大多数河流受 人为影响很大, 如改造河道, 修建水库, 建闸引水灌溉等等. 在这些地区 还有大量人工修建的农灌沟渠, 其水量主要受人工控制. 抚仙湖集水域 尚没有长系列的水文观测, 没有历史观测数据. 从 2004 年 10 月起, 陆续

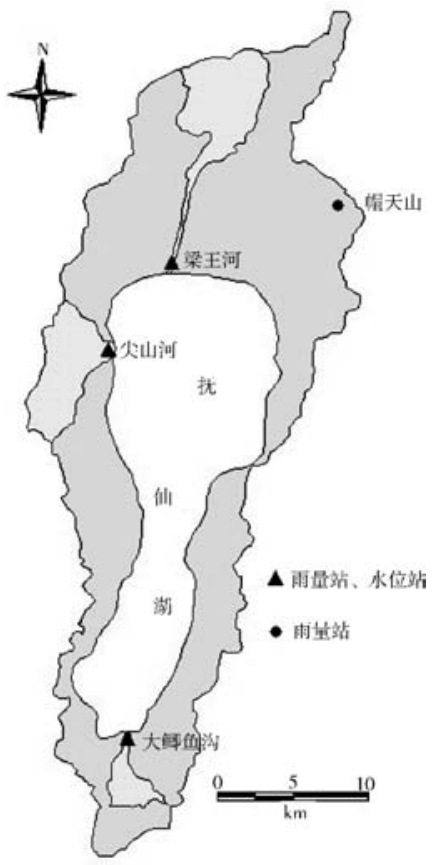

图 1 雨量站、水位观测站示意

Fig. 1 Locations of rainfall and

river stage gauging stations 在梁王河、大鲫鱼沟和尖山河等代表性河流流域安装了水位自动监测记 录仪, 进行高密度数据观测、记录. 位于北岸的梁王河流经农田区, 南岸山区大鲫鱼沟有居民点分布, 尖山 河则是西岸山区最大的天然河流. 它们都具有一定的代表性. 另外, 考虑到地形高程差大造成的降雨空间 
差异, 安装了 4 台雨量记录仪, 尽可能地取得该集水域有代表性地区的雨量、水位数据 ${ }^{[8]}$ (图 1 ). 此外, 在 局部地区还开展了地下水位和土壤含水量的观测, 为更为详细地作水文模拟提供数据基础. 由降雨观测数 据计算得到的四个雨量站点的月降雨量 (表 1) 可知, 受山区特有地形的影响,该集水域各地区的降雨量空 间差异较为明显. 将来在条件允许的情况下有必要进行更多的雨量观测, 从而为研究提供更多更可靠的基 础数据. 目前, 由于研究区域观测资料的限制,拟采用美国农业部水土保持局提出的 SCS 模型来模拟抚仙 湖集水域地表产流量.

表 12005 年 3 月 - 2006 年 2 月观测站月降雨量 $(\mathrm{mm})$ 统计表

Tab. 1 Monthly rainfall measurements $(\mathrm{mm})$ for March 2005-February 2006

\begin{tabular}{ccccccccccccc}
\hline & 3 月 & 4 月 & 5月 & 6 月 & 7月 & 8月 & 9月 & 10 月 & 11月 & 12月 & 1 月 & 2 月 \\
\hline 梁王河 & 52.5 & 8.0 & 4.5 & 234.0 & 179.0 & 287.0 & 55.0 & 89.5 & 9.5 & 46.5 & 0.0 & 2.0 \\
尖山河 & 56.5 & 12.0 & 27.0 & 328.5 & 193.0 & 301.5 & 39.5 & 90.5 & 6.0 & 44.5 & 0.0 & 3.0 \\
大鲫鱼沟 & 35.5 & 7.5 & 19.0 & 249.5 & 100.0 & 150.5 & 33.0 & 95.5 & 5.5 & 35.5 & 0.0 & 4.0 \\
帽天山 & 56.5 & 8.5 & 5.0 & 252.5 & 193.0 & 309.5 & 52.0 & 121.5 & 14.0 & 63.5 & 1.0 & 0.5 \\
\hline
\end{tabular}

\section{$2 \mathrm{SCS}$ 模型及其应用}

\subsection{SCS 模型概述}

SCS 模型是美国农业部水土保持局在二十世纪 50 年代初研制的小流域设计洪水模型. 该模型属于经 验模型,用于计算不同土地利用和土壤类型条件下下垫面的径流量. 目前, 在美国及其他一些国家得到了 广泛的应用. SCS 模型在我国的应用开始于二十世纪 80 年代,主要应用于小流域工程规划、流域水土保持、 城市径流、无资料流域的径流模拟等研究中 ${ }^{[9]}$. 由于我国与美国在气候、土壤、耕作等方面存在地区差异 性, 直接应用美国测定的 CN 值, 不太适合国内的情况, 所以各地在应用时都作了适当的修正 ${ }^{[10-12]}$. 李道峰 等建立了 5 种土地覆被情景模型及 24 组不同气温和降水的情景组合, 分别模拟不同情景下的年径流量, 总 结归纳出了 $\mathrm{SCS}$ 产流模型中 $\mathrm{CN}$ 值在黄河河源区的适用范围, 得到了随着植被覆盖度的增加, 流域年径流 量减小, 蒸发量增加的结论, 为分布式模型在黄河河源区的应用提供了支撑 ${ }^{[13]}$. 晋华等通过对汾河水库上 游的中型流域岗河流域实测降雨、洪水资料的分析,提出了适合其流域产流计算的 CN 值表和用于流域汇 流计算的无因次单位线以及相应的汇流参数关系式 ${ }^{[9]}$. 另有研究者分别利用 SCS 模型对城市化地区, 如深 圳、杭州、上海等的暴雨径流量进行了计算 ${ }^{[14,15]}$, 为城市防洪等水文、水环境问题的研究等提供了参考. 总 体上来说,国内引进 SCS 模型大多是利用其产流模型, 汇流部分则基本没有涉及.

SCS 产流模型的众多优点使它得到了广泛的应用,这也是本研究选择应用的原因:在降雨径流关系上， SCS 模型考虑了流域下垫面的特点, 如土地利用、土壤类型、坡度、植被覆盖等, 及其时空变化对降雨径流关 系的影响; 能简单考虑人类活动 (如土地利用方式及城市化等) 对径流的影响, 也就是说它能针对未来土地 利用情况的变化,预估降雨径流关系的可能变化; 可应用于无资料流域; 模型结构简单, 使用方便,参数 较少.

\section{2 SCS 产流模型的基本原理}

$\operatorname{SCS}$ 曲线参数方程为 ${ }^{[16]}$ :

$$
Q_{\text {surf }}=\frac{\left(R_{\text {day }}-I_{a}\right)^{2}}{\left(R_{\text {day }}-I_{a}+S\right)}
$$

式中, $Q_{\text {surf }}$ 为径流量 $(\mathrm{mm}) ; R_{\mathrm{day}}$ 为日降水深 $(\mathrm{mm}) ; I_{a}$ 为初始吸收量 $(\mathrm{mm})$, 包括雨量在产流前的地表储存、 中途拦截和下渗; $S$ 为持水系数. $S$ 在空间上与土地利用、土壤类型、管理水平和坡度有关, 在时间上和土壤 含水量有关. $S$ 可根据以下公式求得:

$$
S=25.4\left(\frac{1000}{C N}-10\right)
$$

其中, $C N$ 为曲线数. 经验数据表明, $I_{a}=0.2 \mathrm{~S}$, 从而 $\mathrm{SCS}$ 曲线方程可简化为: 


$$
Q_{\text {surf }}=\frac{\left(R_{\text {day }}-0.2 S\right)^{2}}{\left(R_{\text {day }}+0.8 S\right)}
$$

只有在 $R_{\mathrm{day}}>I_{a}$ 才有径流产生, 上述方程中不同的 $\mathrm{CN}$, 降雨量和产流量有着不同的对应关系. $\mathrm{CN}$ 值 是 SCS 模型的主要参数, 用于描述降雨与径流之间的关系, 它已将前期土壤湿润程度 (Antecedent moisture condition, 简称 $\mathrm{AMC}$ ) 、土地利用方式、土壤类型和坡度等因素综合在一起. CN 值把流域的下垫面条件定量 化, 是反映降雨前流域特征的一个综合参数, 模型的开发者收集和分析了大量实测资料, 给出了不同土壤水 分条件下各种土壤类型的 $\mathrm{CN}$ 值查算表. 实际使用时, 根据流域的土壤类型, 即可由流域土地利用方式查得 相应的 CN 值, 再按土壤类型的面积比加权求出流域平均 CN 值, 再由降雨量计算出产流量.

表 2 是根据土壤的最小下渗率划分的 SCS 模型土壤水分组. 前期土壤湿润程度分为 AMC I 、AMC II 和 AMC III 三种, 分别代表了三种前期土壤湿润情况, 即: 流域土壤水文条件为干旱, 但未达到枯萎点, 有良好的 耕作; 发生洪泛时的平均情况, 即洪水出现前夕的土壤水分平均状况; 暴雨前 $5 \mathrm{~d}$ 内有大雨或小雨低温出 现, 土壤几乎呈饱和水文状况. 其中 AMC II 对应的径流曲线数 $\mathrm{CN}_{2}$ 可以直接查到, AMC I 和 AMCIII 的对应 的 $\mathrm{CN}_{1} 、 \mathrm{CN}_{3}$ 的值可分别由 $\mathrm{CN}_{2}$ 求得. 前期土壤湿润程度的具体分类标准见表 3 .

表 2 SCS 模型土壤水分组定义 ${ }^{[17]}$

Tab. 2 Soil hydrologic groups definition of SCS model

\begin{tabular}{ccc}
\hline 土壤类型 & 最小下渗率 $(\mathrm{mm} / \mathrm{h})$ & 土壤质地 \\
\hline $\mathrm{A}$ & $>7.26$ & 砂土、壤质砂土、砂质壤土 \\
$\mathrm{B}$ & $3.81-7.26$ & 壤土、粉砂壤土 \\
$\mathrm{C}$ & $1.27-3.81$ & 砂黏壤土 \\
$\mathrm{D}$ & $0.00-1.27$ & 黏壤土、粉砂黏壤土、砂粘土、粉砂黏土、黏土 \\
\hline
\end{tabular}

表 3 SCS 模型前期土壤湿润程度分类 ${ }^{[17]}$

Tab. 3 Types of antecedent soil moisture condition of SCS model

\begin{tabular}{ccc}
\hline \multirow{2}{*}{ 前期土壤湿润程度 } & \multicolumn{2}{c}{ 前 $5 \mathrm{~d}$ 降水总深度 $(\mathrm{mm})$} \\
\cline { 2 - 3 } & 植被生长阶段 & 其他阶段 \\
\hline AMC I & $<30$ & $<14$ \\
AMC II & $30-50$ & $14-28$ \\
AMC III & $>50$ & $>28$ \\
\hline
\end{tabular}

\section{3 模型建立}

\section{1 子区域的划分}

为了在 SCS 模型中定量区分流域下垫面条件的空间不均匀性, 并把这些不均匀性信息反映到模型的 $\mathrm{CN}$ 值中, 将抚仙湖集水域划分为若干水文响应单元, 分别用 SCS 模型计算其产流量, 最后累加得人湖径流 量. 首先应用 MapInfo/Arc view 软件将抚仙湖集水域的土地利用现状图、土壤类型分布图 (1)等信息数字化 (输人数据的地理坐标均采用高斯一克吕格 6 度分带投影), 土地利用分为牧草地、石山、旱地、疏林地、森 林、水田和水域几种类型 (图 2), 土壤主要有红壤、水稻土、紫色土、棕壤、黄棕壤等(图 3 ). 将土地利用方式 分布图与土壤类型分布图叠加生成一个新的数字地图, 这个数字地图包含了 66 块不规则多边形, 每一个不 规则多边形上对应单一土地利用方式和单一土壤类型, 可以视为一个水文响应单元.

\section{2 参数 $\mathrm{CN}$ 的率定}

经实测调查, 抚仙湖集水域土壤水分组基本确定为 B、C 类. 由前面的分析可知, 在 SCS 模型中各水文 响应单元产流计算只有一个参数 $\mathrm{CN}$, 它是前期土壤湿润程度、土壤类型、土地利用和坡度的函数, $\mathrm{CN}$ 值的 
大小间接地反映了水文响应单元的产流能力. 一般情况下, 当降雨一定时, 产流量较大的水文响应单元, 其 $\mathrm{CN}$ 值也较大, 反之亦然. 取有完整水文观测数据的梁王河和大鲫鱼沟进行模型参数 CN 的率定. 梁王河位 于湖北岸, 流经平原农田区, 流域面积 $33.3 \mathrm{~km}^{2}$; 大鲫鱼沟的位于湖南岸山区, 有居民点分布, 流域面积 8.2 $\mathrm{km}^{2}$ (图 1). 两条河流都很有代表性. 将图 2、3 与图 1 叠加即可得到梁王河与大鲫鱼沟的土地利用方式和 土壤类型分布图, 在确定 $\mathrm{CN}$ 值的前提下, 按面积加权平均法分别计算出梁王河流域和大鲫鱼沟流域的总 $\mathrm{CN}$ 值,利用模型可以分别计算产流量.

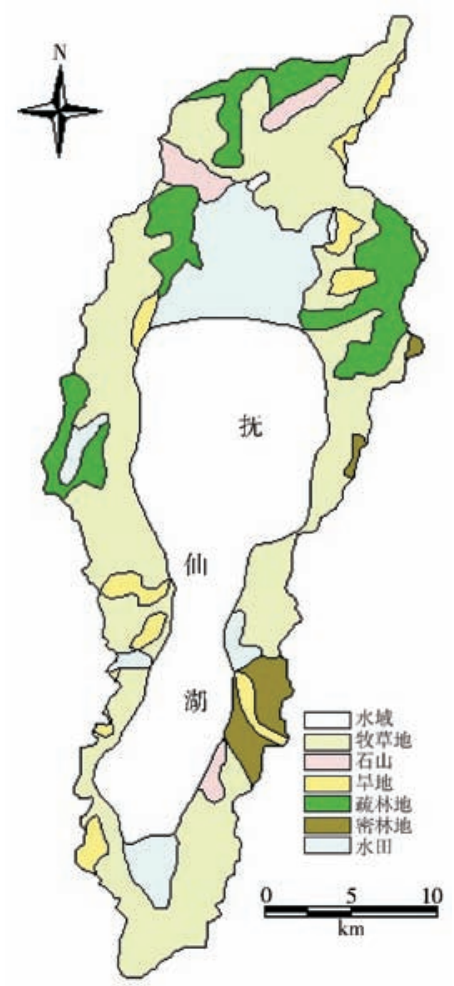

图 2 抚仙湖集水域土地利用现状

Fig. 2 Land uses of Lake Fuxian catchment

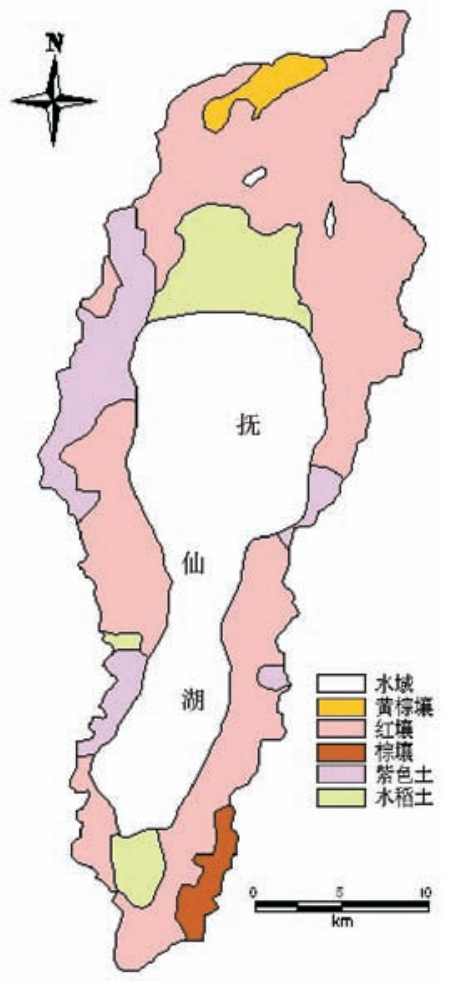

图 3 抚仙湖集水域土壤类型分布

Fig. 3 Soil types of Lake Fuxian catchment

利用 2005 年 3 月 1 日 - 2006 年 2 月 28 日梁王河和大鲫鱼沟流域的雨量、流量观测数据反演流域各种 土地利用方式和土壤类型组合下的 $\mathrm{CN}$ 值. 由于 SCS 模型计算的径流是直接径流, 在对 $\mathrm{CN}$ 参数反算时, 应 先将河道径流中的基流部分扣除. 现场勘察发现, 北岸的梁王河流域地面以下 $1-2 \mathrm{~m}$ 为砂质含水层, 地下 水埋深 $1 \mathrm{~m}$ 左右, 河流接受地下水的补给. 相对而言, 大鲫鱼沟河道浅, 河床水泥衬砌, 与地下水基本没有 水量交换. 所以, 在本次研究中, 只对梁王河的基流量作计算分析. 采用 MODFLOW 模型 ${ }^{[18]}$ 对梁王河的地 下水观测数据进行拟合计算得到基流量, 再从河道观测径流中扣除基流量作为直接径流量, $Q_{\text {surf }}$, 用于反算 $\mathrm{CN}$ 值. 由于梁王河流域多处见砂质含水层, 含水层中呈现地下水自由面, 认为 MODFLOW 是适用的.

$$
\text { 由(3)式知, } 0.2 S=R_{\text {day }}+2 Q_{\text {surf }}-\sqrt{4 Q_{\text {surf }}^{2}+5 Q_{\text {surf }} R_{\text {day }}}
$$

由(4)式计算出 $S$ 值后, 代人 (2) 式即可求出 CN 值. 在试算的过程中发现 $R_{\mathrm{day}} \leqslant 10 \mathrm{~mm}$ 的日降雨基本无直 接径流产生, 因此选择 $R_{\mathrm{day}}>10 \mathrm{~mm}$ 的数据进行 $\mathrm{CN}$ 值的反算. 最后结合各种土壤类型下渗率的相对大小 关系进行综合统计分析, 得到了相应的各水文响应单元的 CN 值 (表 4). 比较模型开发者提供的 CN 值的范 围以及国内一些成功使用 SCS 模型的经验数据,认为表 4 所示的 CN 值是合理的.

将梁王河的基流与 SCS 模型计算得到的径流量叠加,得到总的河道径流量. 大鲫鱼沟不考虑基流. 河 
流径流量的模拟值与实测值的比较以及对应时段的降雨量 (图 4、图 5). 模型能较好地模拟径流的涨落及径 流峰值. 用效率系数 $e\left(e=1-V_{r} / V_{o}, V_{r}\right.$ 为观测值与模拟值的差的方差, $V_{o}$ 为观测值的方差, $e$ 的范围为 1 至 $-\infty$ ( 分别表示 “最优” 至 “最差” 的吻合) 来定量表示模拟值与观测值的吻合程度,则梁王河的效率系数 为 0.874 , 大鲫鱼沟的效率系数为 0.843 , 反映了较好的模型拟合. 同时采用标准化均方差 NRMS( Normalized Root Mean Squared error) 来评价模型的误差. 计算公式为:

$$
\text { NRMS }=\sqrt{\sum_{i=1}^{365}\left(Q_{\text {calc }}-Q_{\text {obs }}\right)_{i}^{2}} /\left\{365\left[\left(Q_{\text {obs }}\right)_{\text {max }}-\left(Q_{\text {calc }}\right)_{\text {min }}\right]\right\}
$$

式中, $Q_{\text {calc }}$ 为计算日流量, $Q_{\text {obs }}$ 为观测日流量, $\left(Q_{\text {obs }}\right)_{\text {max }}$ 为最大观测日流量, $\left(Q_{\text {calc }}\right)_{\text {min }}$ 为最小计算日流量, 365 为模拟天数.

表 4 抚仙湖集水域中等湿润状态下不同土壤类型和土地利用方式下的 $\mathrm{CN}$ 值

Tab. 4 Calibrated CN values for different landuses and soil types

\begin{tabular}{cccccccc}
\hline \multirow{2}{*}{ 土壤类型 } & \multicolumn{7}{c}{ 土地利用方式 } \\
\cline { 2 - 8 } & 牧草地 & 石山 & 早地 & 疏林地 & 密林地 & 水田 & 水域 \\
\hline 红壤 & 82 & 93 & 87 & 72 & 68 & 74 & 98 \\
水稻土 & 78 & 92 & 83 & 70 & 66 & 72 & 98 \\
紫色土 & 74 & 91 & 78 & 68 & 64 & 69 & 98 \\
棕壤 & 70 & 89 & 73 & 66 & 62 & 67 & 98 \\
黄棕壤 & 66 & 88 & 68 & 64 & 60 & 64 & 98 \\
\hline
\end{tabular}
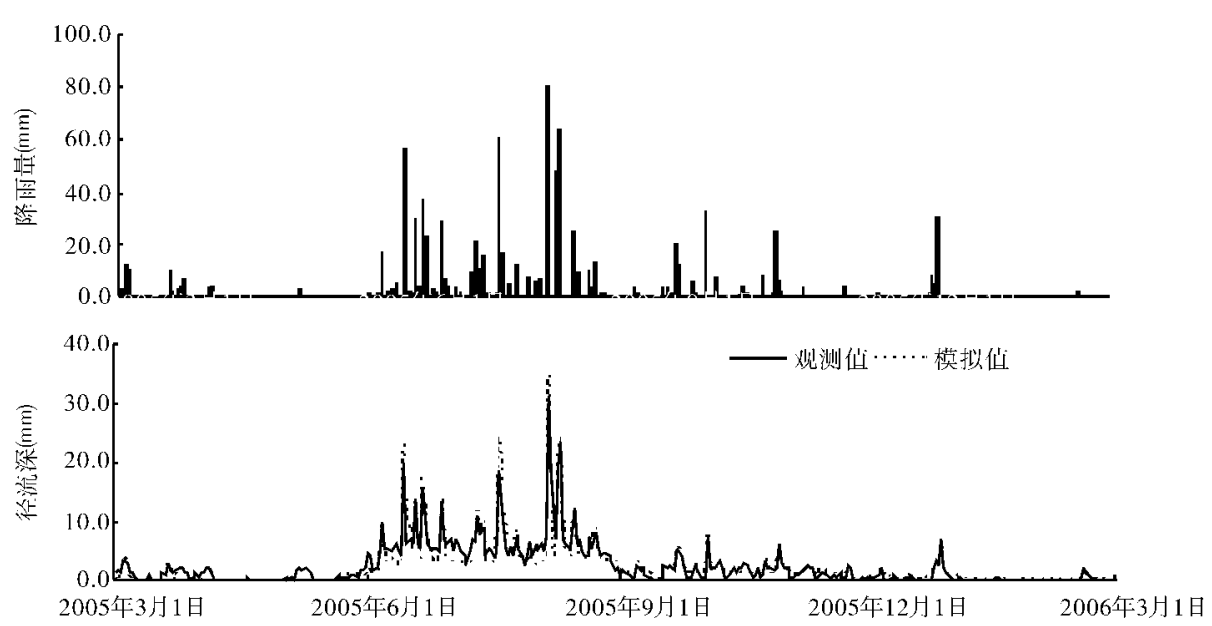

图 4 梁王河模拟径流量与观测值的比较

Fig. 4 Comparison of modeled and observed runoff for Liangwanghe

经计算,得到梁王河的 NRMS 为 0.00215 ,大鲫鱼沟的 NRMS 为 0.00244 ,较小的数值表示了较好的模 拟效果. 计算时段内梁王河流域总面雨量 $967.5 \mathrm{~mm}$, 模型计算总径流深为 $551.5 \mathrm{~mm}$, 径流系数为 0.570 . 大鲫鱼沟流域总面雨量 $735.4 \mathrm{~mm}$,模型计算总径流深为 $343.5 \mathrm{~mm}$, 径流系数为 0.467 .

\section{3 整个集水域径流计算}

将模型应用到除梁王河和大鲫鱼沟流域外的其它区域上,除北岸平原区外,都忽略基流. 对平均坡度 大于 $5 \%$ 的区域,对 $\mathrm{CN}$ 值作了坡度校正：

$$
C N_{2 S}=\frac{\left(C N_{3}-C N_{2}\right)}{3}[1-2 \exp (-13.86 s l p)]+C N_{2}
$$

式中, $C N_{2 S}$ 为经过坡度修正后的平均土壤水分条件下的 $\mathrm{CN}$ 值; $s l p$ 为水文响应单元的平均坡度. 


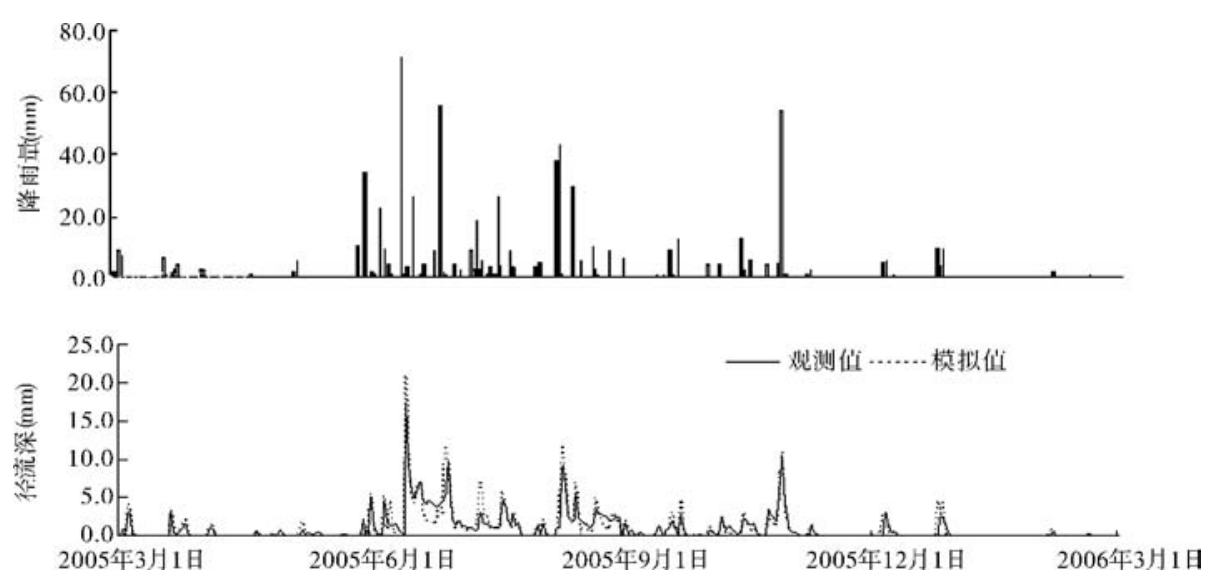

图 5 大鲫鱼沟模拟径流量与观测值的比较

Fig. 5 Comparison of modeled and observed runoff for Dajiyugou

根据每块子区域的 $\mathrm{CN}$ 值及逐日降雨量, 分别计算出其产流量并求和, 即得整个湖泊陆地集水域的总 产流量. 考虑到研究中的四个雨量观测站点的空间分布比较均匀, 而且有较强的代表性, 采用泰森多边形 法把集水域划分成四个区域,每个区域采用相应的雨量观测数据进行模型计算. 计算得出, 2005 年 3 月 1 日 -2006 年 2 月 28 日湖泊集水域平均面雨量 $970 \mathrm{~mm}$, 集水域面积 $453.2 \mathrm{~km}^{2}$, 所以总降雨量为 $4.40 \times 10^{8}$ $\mathrm{m}^{3}$, 用 SCS 模型计算出的总地表径流量为 $1.74 \times 10^{8} \mathrm{~m}^{3}$, 集水域平均径流系数为 0.395 .

通过计算得知,土地利用为牧草地且土壤类型为红壤的水文响应单元径流系数约为 0.434 ,接近平均 径流系数, 这跟集水域内以该类型区域为主有关, 这种水文响应单元在北部山区和东西两岸都有广泛分布, 这部分区域占总集水域面积的 $41.3 \%$. 东西两岸若干散流区就属于该类型. 在湖泊南北两岸最典型的是 土地利用为水田且土壤类型为水稻土的区域, 这种类型区域的径流系数约为 0.350 . 此外, 土地利用为牧草 地且土壤类型为紫色土的水文响应单元径流系数约为 0.363 , 明显小于同为牧草地而土壤类型为红壤的水 文响应单元径流系数 0.434 . 而土壤类型为红壤的林地径流系数小于 0.330 , 这反映了林地 $\mathrm{CN}$ 较小, 体现了 森林对产流的重要影响. 采用 SCS 模型计算的整个抚仙湖集水域 2005 年 3 月 1 日 - 2006 年 2 月 28 日的逐 日人湖径流量模拟结果 (图 6). 可见雨季旱季人湖径流量的差别非常大.

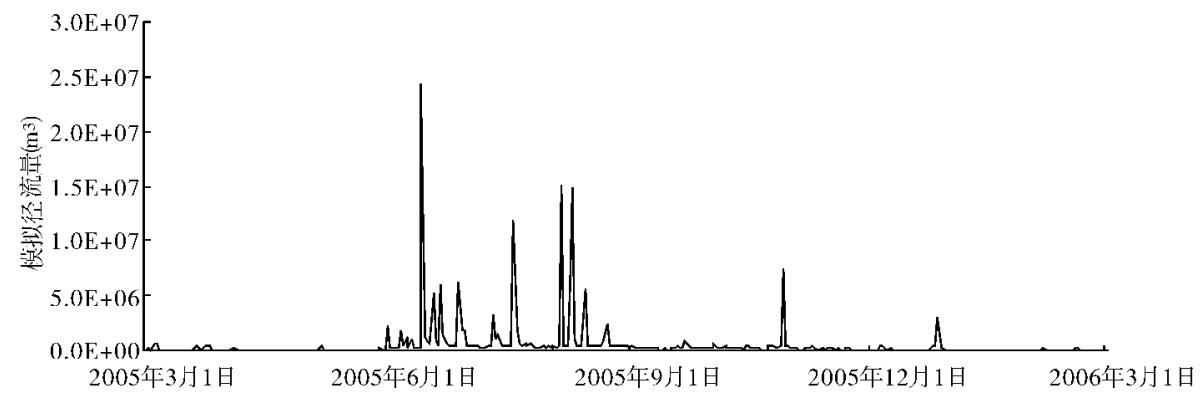

图 6 抚仙湖集水域日入湖地表径流量模拟值

Fig. 6 Daily modeled surface runoff of Lake Fuxian catchment

\section{4 讨论及结论}

$\mathrm{CN}$ 值是 SCS 模型的主要参数, 反映降雨一径流的关系, 是土壤前期湿润程度、土地利用、土壤类型等因 素的函数. 一般来说, 降雨一定时, $\mathrm{CN}$ 值越大, 径流越大, 即 $\mathrm{CN}$ 值越大的下垫面产流能力越大. 土壤越干, 
下垫面条件对降雨径流关系的影响越大. 降雨量越大,下垫面条件对降雨径流关系的影响越小. 作为日产 流模型, SCS 模型没有考虑降雨历时和雨强对初损及 CN 值的影响, 会不可避免地影响模型的精度及使用效 果. 从模型对径流过程的拟合情况来看, 对于洪水和中水部分拟合较好, 而对个别低水值尤其是洪水退水 后的径流模拟不好,这可能跟基流及人类活动影响有关. 原因可能是该模型没有水源划分结构,应该进一 步完善模型与地下水模型的结合应用. 另外,前期降雨对土壤湿润状况的影响是一个很复杂的过程,在模 型中采用水文响应单元前 $5 \mathrm{~d}$ 总雨量作为土壤前期湿润程度 (AMC), 往往带有一定的经验性, 而且模型中 AMC 只分了 3 级, 具有跳跃性, 从而降低了产流模拟的精度, 这方面的研究还有待进一步深人.

研究中采用 MODFLOW 模型对梁王河基流进行模拟, 由于地下水观测数据的限制,基流的模拟可能带 有一定的误差, 这将对 SCS 模型的模拟精度产生一定的影响, 表现为各水文响应单元的 CN 值具有一定的 不确定性. 在获取更多数据后, 可以对模型作进一步的细化. 另外, 由于目前观测时段较短, 只能进行模型 的率定,无法再选取独立时段作模型验证,这将在今后进一步完善.

以往国内研究者在应用 SCS 模型时,或者对模型有关公式进行改进 ${ }^{[12,15]}$,或者通过人工降雨等实验方 法得到单一坡面的 CN 值 ${ }^{[1,20]}$, 应用的区域包括黄河流域 ${ }^{[9-13]}$ 、城市化地区 ${ }^{[14,15]}$ 等,但尚未见到 SCS 模型 在湖泊集水域进行径流量的模拟,在抚仙湖集水域这样的复杂区域进行 SCS 模型的应用是一次尝试. 根据 模拟过程和计算结果可知, SCS 模型考虑了下垫面的空间非均一性,对于研究降雨 - 径流关系的计算是一 个较为有效的模型. 模型在云南抚仙湖集水域局部区域上作了检验,通过模型计算得到的抚仙湖集水域 2005 年 3 月 1 日 - 2006 年 2 月 28 日地表径流量为 $1.74 \times 10^{8} \mathrm{~m}^{3}$, 径流系数为 0.395 ,与观测数据的比较得 出, 该模型能较为满意地模拟径流过程. 该模型能够反映流域空间非均匀性对产流的影响,这是以往采用 单一径流系数法计算集水域地表径流量不能做到的. 对于抚仙湖集水域这样一个资料比较缺乏的地区, 本 研究在一定程度上揭示了产流的空间分布. 该方法不但能计算每条人湖河流流域的河道径流量, 而且能计 算河道间散流区的人湖径流量,这将为以后进一步开展的现场观测提供针对性的指导,也能为以后分布式 模型的建立提供数据基础. 同时, 为估算不同土地利用类型污染物的产出和人湖污染负荷提供径流依据.

\section{5 参考文献}

[1] Viney N R, Sivapalan M. Modelling catchment processes in the Swan-Avon river basin. Hydrological Processes, 2001, 15: $2671-2685$.

[2] Wolf J, Beusen A H W, Groenendijk P et al. The integrated modeling system STONE for calculating nutrient emissions from agriculture in the Netherlands. Environmental Modelling \& Software, 2003, 18: 597 -617 .

[3] Baginska B, MilneHome W, Cornish P S. Modelling nutrient transport in Currency Creek, NSW with AnnAGNPS and PEST. Environmental Modelling \& Software, 2003, 18: $801-808$.

[4] Tolson B A, Shoemaker C A. Watershed modeling of the Cannonsville Basin using SWAT2000: Model development, calibration and validation for the prediction of flow, sediment and phosphorus transport to the Cannonsville Reservoir. Technical Report, version 1. 0, School of Civil and Environmental Engineering, Cornell University, 2004.

[5] 中国科学院南京地理与湖泊研究所. 抚仙湖. 北京: 海洋出版社, 1990 .

[6] 郑 祥,方增福. 玉溪市抚仙湖沿岸景观生态建设规划. 玉溪师范高等专科学校学报, 2000,16(3): $91-94$.

[7] 侯长定, 莫绍周, 陈怀芬等. 抚仙湖富营养化与人湖河水处理研究. 云南环境科学, 2004,23(增刊 1): $98-100$.

[8] 张 奇, 徐力刚. 抚仙湖集水域径流过程的观测与模拟. 科学技术与工程, 2005, 5 (24): 1946 -1950 .

[9] 晋 华,孙西欢,李仰斌. SCS 模型在岗河流域的应用研究. 太原理工大学学报,2003,34(6): 735 -736 . 
[10］杨桂莲,郝芳华,刘昌明等. 基于 SWAT 模型的基流估算及评价一一洛河流域为例. 地理科学进展, $2003,22(5): 463-471$.

[11] 贺宝根, 周乃晟, 高效江等. 农田非点源污染研究中的降雨径流关系. 环境科学研究,2001, 14(3) : 49 -51 .

[12] 王白陆. SCS 产流模型的改进. 人民黄河,2005,27(5): 24-26.

[13] 李道峰,田 英,刘昌明. 黄河河源区变化环境下分布式水文模拟. 地理学报,2004,59(4): 565 -573 .

[14] 袁 艺,史培军, 刘颖慧等. 土地利用变化对对城市洪涝灾害的影响. 自然灾害学报, 2003,12(3):6 -13 .

[15] 贺宝根. 城市化地区径流系数及其应用. 上海环境科学,2003,22(7): $472-475$.

[16] Neitsch S L, Arnold J G, Kintry J R et al. Soil and water assessment tool theoretical documentation, Version 2000. Texas Water Resources Institute, College Station, Texas, 2002, TWRI Report TR - 191 .

[17] 王晓燕. 非点源污染及其管理. 北京: 海洋出版社,2003:43-48.

[18] McDonald M G, Harbaugh A W. A modular three-dimensional finite-difference ground-water flow model. U. S. Geological Survey Techniques of Water Resources Investigations, Book 6, Chapter A1, Washington DC, 1988.

[19] 王兴鹏,马 轶, 张维江等. SCS 模型在黄土丘陵因子径流场中的应用. 宁夏工程技术,2005,4(2): 157 $-159$.

[20] 张美华,王晓燕, 秦福来. SCS 模型在密云石匣试验小区降雨径流量估算中的应用. 首都师范大学学 报(自然科学版),2004,25:155-158. 